\title{
Is the cold chain for vaccines maintained in general practice?
}

\author{
E A Haworth, R Booy, L Stirzaker, S Wilkes, A Battersby
}

\begin{abstract}
Objective-To investigate the cold chain for vaccines and compliance with the local code of practice for storage.

Design-In a random sample of general practices orders for live vaccines (oral polio and measles, mumps, and rubella) were accompanied by a cold chain monitor which was activated on leaving the supplying pharmacy. The monitors were read at specified intervals and when all vaccines in the order had been used. Structured interview was used to check compliance with the local code of practice on storage.
\end{abstract}

Setting-West Berkshire and Aylesbury Vale district health authorities.

Subjects-16 $(25 \%)$ general practices in West Berkshire, and $13(50 \%)$ in Aylesbury Vale.

Main outcome measures-Compliance with code of practice. Changes in the cold chain monitor.

Results-For six key requirements within the code of practice compliance varied from $70 \%$ to $0 \%$. Only 16 of 29 practices had a named person responsible for vaccine storage and only four were aware of the local code of practice. Vaccine was stored for longer and more breaks in the cold chain occurred in West Berkshire than in Aylesbury Vale. The potency of some vaccines in 10 of 26 orders became suspect before use.

Conclusions-Knowledge of appropriate management of the cold chain in two districts was poor. Breaks in the chain were more frequent and compromised potency more likely when vaccine had been stored for more than eight weeks. Problems in maintaining the cold chain indicate the need for continuing audit, which should become a prerequisite for payments to general practitioners for immunisation.

Authority, Prospect Par

Hospital, Reading RG3 4EJ

E A Haworth, consultant in communicable disease control $S$ Wilkes, public health nurse

John Radcliffe Hospital, Oxford OX3 9DU

$\mathrm{R}$ Booy, paediatric research fellow

Aylesbury Vale Health Authority, Aylesbury HP19 3DX

L Stirzaker, senior registrar in public health medicine

World Health Organisation, Riverside Cottage, Tellisford, Bath BA3 6RI

A Battersby, consultant in operations management

Correspondence to: Dr Haworth.

The potency of vaccines depends on maintaining the cold chain-that is, a prescribed temperature range during distribution from manufacture to use. The temperature during transport and storage should be kept at $0-4^{\circ} \mathrm{C}$ for oral polio vaccine and $2-8^{\circ} \mathrm{C}$ for other vaccines. Recent studies in England and America have shown failure to comply with recommended guidelines on the handling of vaccines in general practice, ${ }^{12}$ community clinics, ${ }^{2}$ and paediatric practice. ${ }^{3}$

Without systematic monitoring on a wide scale it is difficult to know if failure of vaccines is due to breaks in the cold chain. Probable cases have been described, ${ }^{4}$ however, and testing of live vaccines stored in the community has shown reduced potency because of improper handling. ${ }^{5}$ Primary vaccine failure has been proposed as a major reason for the large proportion of cases of measles which have occurred among vaccinated children and teenagers in the recent epidemic in the United States. ${ }^{6}$

The World Health Organisation has developed cold chain monitors as a managerial tool for monitoring cumulative temperature exposure of vaccines. ${ }^{7}$ Studies with these monitors in many tropical countries as well as in countries of the WHO's European region have shown important breaks in the cold chain ${ }^{8}$ (unpublished data). To investigate the integrity of the cold chain in two districts of the Oxford Regional Health Authority we used cold chain monitors and assessed compliance with the code of practice for storage of vaccine.

\section{Method}

In 1990 a pilot study was undertaken in three general practices in West Berkshire to gain experience in the use of WHO cold chain monitors and test a structured questionnaire. During the summer of 1991 random samples representing a quarter (16) of practices within West Berkshire Health Authority (population 460000 ), and half (13) of practices in Aylesbury Vale Health Authority (population 150000) were selected from the Berkshire and Buckinghamshire Family Health Services Authority lists, respectively, by using computer generated random numbers. Community clinics were excluded from the study as there are none in West Berkshire and only $5 \%$ of infants are immunised in such clinics in Aylesbury Vale.

All general practices were invited by letter to participate in the study. Three in West Berkshire refused and were excluded before selection; one practice in Aylesbury Vale refused after sample selection. A temperature monitor, manufactured by $3 \mathrm{M}$ and shown by laboratory testing to be reliable, ${ }^{9}$ was included with every order from study practices for measles, mumps, and rubella and oral polio vaccines. Monitors were activated on leaving the district pharmacy. An investigator (SW or LS) was telephoned by the practice receptionist or a practice nurse as soon as the vaccine arrived. The monitor was read by the informant and recorded by the investigator. Practices were asked to keep the cold chain monitor in the refrigerator with the order of vaccines it accompanied
Selected requirements from the codes of practice for storage of vaccines

- Designate a named person to be responsible for vaccines

- A maximum-minimum thermometer should be placed in the middle of the refrigerator

- Read, record, and reset thermometer daily

- If defrosting of the refrigerator is necessary, carry this out regularly and during the defrost store vaccine in an alternative refrigerator or cold box

- Ensure that the electrical supply to the refrigerator cannot be accidentally interrupted

- If transfer of vaccines between immunisation clinics is necessary, use a cool box and minimise transit time 
until all those vaccines had been used. One to two weeks later one of the authors (SW or LS) visited the practice to complete a short structured questionnaire about vaccine storage and to read the monitor(s). For the assessment of compliance with the local code of practice, ${ }^{1011}$ we selected six specific requirements common to both districts (box). Four of these are included in the Department of Health's handbook Immunisation against infectious disease. ${ }^{12}$ The questionnaire also asked whether the practice nurse was familiar with the local code of practice, how vaccines were delivered to the practice, and what in addition to vaccines was stored in the vaccine refrigerator.

If the order had not been completely used a third monitor reading was obtained eight weeks after delivery by an investigator (SW) visiting the practice in West Berkshire or by an investigator (LS) telephoning the practice nurse in Aylesbury Vale. Whenever all doses in the order had been used, a final monitor reading was obtained.

We followed WHO guidelines in interpreting the monitor. ${ }^{7}$ The monitor has windows $(\mathrm{A}, \mathrm{B}, \mathrm{C})$ which progressively change colour on exposure to temperatures above $10^{\circ} \mathrm{C}$. The entire window must change

TABLE I-Changes in monitors to check cold chain for vaccines at specified temperatures and exposure times

\begin{tabular}{lcc}
\hline & \multicolumn{2}{c}{ Exposure time (days): } \\
\cline { 2 - 3 } Monitor reading & At $12^{\circ} \mathrm{C}$ & At $21^{\circ} \mathrm{C}$ \\
\hline A & 3 & 2 \\
B & 8 & 6 \\
A-reading means window A completely changed. & 11 \\
B-reading means A and B windows completely changes. & \\
C-reading means A, B and C windows completely changed. &
\end{tabular}

TABLE II-Compliance with storage guidelines for vaccines

\begin{tabular}{lccccc}
\hline & \multicolumn{2}{c}{ West Berkshire } & & \multicolumn{2}{c}{ Aylesbury Vale } \\
\cline { 2 - 3 } \cline { 6 - 7 } Guidance & $\begin{array}{c}\text { Total No of } \\
\text { refrigerators }\end{array}$ & $\begin{array}{c}\text { No (\%) } \\
\text { compliant }\end{array}$ & & $\begin{array}{c}\text { Total No of } \\
\text { refrigerators }\end{array}$ & $\begin{array}{c}\text { No (\%) } \\
\text { compliant }\end{array}$ \\
\hline Named person responsible for vaccines & 16 & $8(50)$ & & 13 & $8(62)$ \\
Any thermometer in refrigerator & $20^{\star}$ & $14(70)$ & & 13 & $7(54)$ \\
Max-min thermometer in refrigerator & $20^{\star}$ & $2(10)$ & & 13 & $3(23)$ \\
Thermometer read and recorded daily & 14 & $2(14)$ & & 7 & $0(0)$ \\
Refrigerator requires defrosting & 20 & $8(40)$ & 13 & $7(54)$ \\
When defrost required vaccines kept cool & 8 & $5(63)$ & 7 & $4(57)$ \\
Power supply protected & 20 & $13(65)$ & 13 & $6(46)$ \\
When vaccine transfer necessary cool box used for & & $0(0)$ & & 4 & $1(25)$ \\
\hline transport & 5 & 0 &
\end{tabular}

${ }^{\star}$ Four practices had two refrigerators for vaccines.

TABLE III-Cold chain monitor readings in West Berkshire and Aylesbury Vale general practices

\begin{tabular}{|c|c|c|c|c|c|c|}
\hline Details of readings & Clear & A & B & C & Unknown & Total \\
\hline \multicolumn{7}{|c|}{ West Berkshire } \\
\hline Polio: & & & & & & \\
\hline $\begin{array}{l}\text { Readings at } 1-2 \text { weeks } \\
\text { Readings when order finished: }\end{array}$ & 9 & 3 & 1 & & & $13^{\star}$ \\
\hline$<8$ Weeks & 2 & & 1 & & & 3 \\
\hline$>8$ Weeks & 2 & 1 & 5 & 2 & & 10 \\
\hline \multicolumn{7}{|l|}{ Measles, mumps, and rubella } \\
\hline $\begin{array}{l}\text { Readings at } 1-2 \text { weeks } \\
\text { Readings when order finished: }\end{array}$ & 10 & 3 & & & & $13^{\star}$ \\
\hline$<8$ Weeks & 1 & 2 & & 1 & & 4 \\
\hline$>8$ Weeks & 3 & & 2 & 3 & 1 & 9 \\
\hline \multirow{2}{*}{\multicolumn{7}{|c|}{ Aylesbury Vale }} \\
\hline Polio: & & & & & & \\
\hline $\begin{array}{l}\text { Readings at } 1-2 \text { weeks } \\
\text { Readings when order finished: }\end{array}$ & 12 & 1 & & & & $13+$ \\
\hline $\begin{array}{l}<8 \text { Weeks } \\
>8 \text { Weeks }\end{array}$ & 10 & $\begin{array}{l}2 \\
1\end{array}$ & & & & 12 \\
\hline \\
\hline $\begin{array}{l}\text { Readings at } 1-2 \text { weeks } \\
\text { Readings when order finished: }\end{array}$ & 11 & 1 & & & & $12 \dagger$ \\
\hline$<8$ Weeks & 7 & 2 & 1 & & & 10 \\
\hline$>8$ Weeks & & 1 & & & 1 & 2 \\
\hline
\end{tabular}

from clear to blue to be recorded. Table I shows the readings for two specified temperatures and exposure times. A B reading indicated that the potency of oral polio vaccine had become suspect and should be tested before use. A C reading indicated that both oral polio and measles, mumps, and rubella vaccines should be tested before use.

The $\chi^{2}$ test (with Yates's correction) and Fisher's exact test (when numbers were small) were used in comparisons.

\section{Results}

Table II shows that compliance with selected storage requirements for vaccines was generally low. In only four practices were staff aware of the local code of practice for vaccine storage and of these only two had a copy. Ten of 29 practices had at least some of their vaccines supplied to them by post, though none of the live vaccines monitored in this study had been posted. Nine of the 33 vaccine refrigerators (four practices had two refrigerators) also had food and drink stored in them, and 17 contained clinical specimens.

No important breaks in the cold chain occurred between vaccines leaving the district pharmacy and arriving at the general practice. Table III shows the monitor readings obtained one to two weeks after the arrival of vaccines and again when the order was completely used. For West Berkshire and Aylesbury Vale combined, practices which kept oral polio vaccine for more than eight weeks were more likely to have final monitor readings which indicated compromised potency $(p=0.003)$. In addition, significantly more practices in West Berkshire than in Aylesbury Vale had not used up their order eight weeks after delivery (oral polio $X^{2}=10.08, p=0.001$; measles, mumps, and rubella $\chi^{2}=4 \cdot 29, p=0 \cdot 04$ ).

\section{Discussion}

The results show that vaccines had not been stored properly in randomly selected general practices in two health districts and that the compliance with storage guidelines was unacceptable. The low percentage of practices with a named person responsible for care of vaccines and the even lower percentage of named persons who were familiar with the code of practice are likely reasons. Most practice refrigerators stored food, drink, and clinical specimens as well as vaccines. This must mean that refrigerators were opened frequently and that both the code of practice for storing vaccines and the food hygiene regulations were broken. Although most refrigerators included a thermometer, only a few had a maximum-minimum thermometer, and in only two was the reading taken and recorded daily.

In general, vaccines were kept for too long, particularly in the larger district, West Berkshire. Some oral polio and some measles, mumps, and rubella vaccine, kept for more than eight weeks in seven and three practices, respectively, required testing for potency before use. $^{7}$

After this study revised guidelines for storage of vaccines were circulated to all general practices in both districts. An audit of compliance has already been carried out in Aylesbury Vale and distinct improvements have been shown (table IV). All but one in 24 practices surveyed now have a named person responsible for vaccines, most have a thermometer $(54 \%$ maximum-minimum) in their refrigerator, and most read it daily. In West Berkshire a follow up survey is planned.

The Department of Health is introducing a new system for distributing vaccines for the childhood programme from a single central source, which is now 
partly operational. General practitioners may order and receive supplies direct from this source every fortnight. If such a system can be fully implemented and maintained, the problems of overordering vaccines and excessive storage time should be overcome. Many general practitioners, however, are understandably sceptical because of previous shortages and delays in supply of vaccine from a central source.

TABLE IV-Results from audit of compliance with vaccine storage guidelines in Aylesbury Vale

\begin{tabular}{lcc}
\hline Guidance & $\begin{array}{c}\text { No (\%) in } \\
\text { August 1991 } \\
(\mathbf{n}=25)\end{array}$ & $\begin{array}{c}\text { No (\%) in } \\
\text { August 1992 } \\
(\mathrm{n}=24)\end{array}$ \\
\hline Named person responsible for vaccines & $14(56)$ & $23(96)$ \\
Thermometer & $11(44)$ & $19(80)$ \\
Max-min thermometer enclosed & $5(20)$ & $13(54)$ \\
Daily readings of temperature & $1(4)$ & $12(50)$ \\
Reading recorded & $0(0)$ & $8(33)$ \\
Cool box available & $1(4)$ & $11(46)$ \\
\hline
\end{tabular}

Measles, mumps, and rubella are highly contagious and to be prevented require high levels of uptake with an efficacious vaccine. ${ }^{13}$ Since 1989 there have been numerous reports of outbreaks of measles in the United States and, although this upsurge is thought mainly to be because of poor rates of vaccination in preschool children, a large proportion of cases have occurred in school aged immunised children. The main reason proposed for infection after immunisation is primary vaccine failure. Breaks in the cold chain, resulting in reduced potency are known to contribute to this. ${ }^{5}$ In the United Kingdom, with the uptake of measles, mumps, and rubella vaccine now over $90 \%$, the incidence of both measles and mumps is low but these infections remain endemic. In view of the recent change in the United Kingdom to a slightly less immunogenic (Jeryl-Lynn strain) mumps virus vaccine, ${ }^{13}$ any other factor which threatens efficacy, such as impairment of the cold chain, must be minimised.

In this study of a random sample of practices in districts where the standard of general medical practice is otherwise high we have found frequent poor care of vaccines. This problem is likely to be widespread. Although guidelines on appropriate storage of vaccines have been issued, ${ }^{70-12}$ minimum standards have not been agreed. Demonstration of maintenance of the cold chain could be made necessary for target payments for immunisation in general practice.

\section{Clinical implications}

- Breaks in the cold chain reduce the potency of vaccines and contribute to primary vaccine failure

- Primary vaccine failure is the main reason for infection after immunisation

- In this study breaks in the cold chain were more frequent and the potency of the vaccine was more likely to be compromised when vaccines had been stored for more than eight weeks

- In 10 out of 26 general practices the potency of some vaccines became suspect before use

- In general practice continuing audit of management of the cold chain for vaccines is necessary and should become a prerequisite for immunisation payments

We are grateful for the help given by Mrs Karen Livett, Mrs Anne Phillips, pharmacy staff in both districts, and all practices that cooperated in the study. We also thank the WHO for supplying the cold chain monitors, Dr R T MayonWhite for reviewing draft manuscripts, and Mrs Carole Barr for typing them.

1 Thakker $\mathrm{Y}$, Woods S. Storage of vaccines in the community: weak link in the cold chain? BMf 1992;304:756-8.

2 Hunter S. Storage of vaccines in general practice. BMF 1989;299:661-2.

3 Bishai DM, Bhatt S, Lee T, Miller MD, Hayden GF. Vaccine storage practices in pediatric offices. Pediatrics 1992;89:193-6.

4 Lerman SJ, Gold E. Measles in children previously vaccinated against measles. FAMA 1971;216:1311-4.

5 Krugman RD, Meyer BC, Enterline JC, Parkman PD, Witte J, Meyer HM. Impotency of live virus vaccines as a result of improper handling in clinical practice. $\mathcal{I}$ Pediatr 1974;85:512-4.

6 Centres for Disease Control and Prevention. Measles-United States, first 26 weeks 1989. MMWR 1989;38:863-72.

7 WHO Expanded Programme on Immunisation. Vaccine cold chain monitor EPICCIS/85. 1. Geneva: World Health Organisation, 1985.

8 Lugosi L, Battersby A. Transport and storage of vaccines in Hungary. Bull World Health Organ 1990;68:431-9.

9 WHO Expanded Programme on Immunisation. Chemical indicators for monitoring the cold chain EPI/CCIS/83/Rev. 1. Geneva: World Health Organisation, 1987.

10 West Berkshire Health Authority. Guidelines on the storage of vaccines. Reading: West Berkshire Health Authority, 1989.

11 Oxford Regional Health Authority. Guidelines on the storage of vaccines. Oxford: Oxford Regional Health Authority, 1990.

12 Joint Committee on Vaccination and Immunisation. Immunisation against infectious disease. London: Department of Health, HMSO, 1990.

13 Nokes DJ, Anderson RM. Vaccine safety versus .vaccine efficacy in mass immunisation programmes. Lancet 1991;ii:1309-12.

(Accepted 13 May 1993)

\section{SOUND BITES}

\section{Doctors' hobbies}

The obituary columns of the $B M \mathcal{F}$ provide a convenient index to the extracurricular activities of our colleagues. The hobbies of the 404 doctors listed in 1992 were gardening $(20 \%)$; literary, including literature, reading, history, languages, poetry, writing $(18 \%)$; music $(15 \%)$; fishing $(7 \%)$; painting $(7 \%)$; sailing $(6 \%)$; church affairs $(5 \%)$; walking, carpentry, community affairs, Rotary and Freemasonry, travel (4\%); photography, chess, bridge (3\%); antiques, swimming, skiing, football, tennis, mountaineering, food and wine $(2 \%)$. Others were cooking (four cases), hockey (five), ornithology (five), riding, fast cars, flying, house repairing, engineering, horology, campanology, shooting, bowls, cycling, computers, philosophy (two each), and archery, ice skating, lacrosse, polo, fox hunting, vintage cars, astronomy, and philosophy (one each).

Many had multiple hobbies: $15 \%$ had two, $14 \%$ three, $10 \%$ four, and $4 \%$ five. Some were veritable polymaths.

Dr JFC was a golfer, cricketer, rugby player, violinist, pianist, singer and linguist, and an expert bridge player. Dr GRE was a clarinettist, a philosopher, etymologist, horticulturalist, and archaeologist. Dr AWH was a pianist, gardener, actor, hypnotist, member of MENSA, and an evangelist. Dr ANH exhibited paintings at the Royal Academy and was a sailor, polo player, and master of foxhounds.

The variety of hobbies described is fairly representative of the contemporary middle classes, though the literary level is somewhat below that for the other learned professions. Perhaps doctors are more interested in humanity than in the humanities.-ALBERT DAVIS is a consultant gynaecologist in London

We are delighted to receive submissions of up to 600 words on $A$ paper (or patient or book) that changed my practice, $A$ memorable patient, The one message I would like to leave behind, or related topics. 